\title{
Los sefardíes y el hebreo: errores gráficos y de comprensión en las versiones judeoespañolas de cuatro midrašim hebreos*
}

\author{
Elena Romero** \\ ILC, CSIC (Emérita)
}

ORCID ID: https://orcid.org/0000-0003-4798-0459

En este artículo y a través de ejemplos basados en las versiones sefardíes de cuatro midrašim hebreos -Guedulat Mošé, Petirat Mošé, Ma 'asé Yerušalmi y Séfer Ben-Sirá-, se pretende mostrar el desconocimiento del hebreo del que, en ocasiones, hacen gala impresores y manuscribas sefardíes. La argumentación se basa en dos tipos de errores: 1) los gráficos, en los que las palabras hebreas se escriben a la «fonética», lo que especialmente en el caso de los impresos induce a pensar en una composición tipográfica al dictado; y 2) los que muestran la incomprensión de textos hebreos a la hora de traducirlos al judeoespañol, lo que puede dar como resultado pasajes, bien incomprensibles, bien hilarantes por disparatados.

PAlabras ClaVe: literatura sefardí aljamiada; traducciones sefardíes del hebreo; Midráš; Guedulat Mošé; Petirat Mošé; Ma 'asé Yerušalmí; Séfer Ben-Sirá.

Sephardim and Hebrew: Graphic and Comprehension Errors in the JudeoSpanish Versions of Four Hebrew Midrashim.- In this article, by means of examples taken from the Judeo-Spanish versions of four Hebrew midrashim - Gedulat Moshe, Petirat Moshe, Ma 'asé Yerushalmi and Sefer Ben-Sira -, I pretend to show the ignorance of Hebrew that, sometimes, is shown by Sephardic printers and scribes. My argument is based on two types of errors: 1) graphic errors of Hebrew words written in a phonetic way, what - specially in the case of printed texts - suggests some kind of typographical composition taking dictation; and 2) comprehension errors when translating Hebrew texts into Judeo-Spanish, what results in unintelligible or crazy passages.

* El presente artículo ha sido elaborado en el marco del Proyecto de Investigación del Plan Nacional «Sefarad, siglo Xxi (2017-2020): Edición y estudio filológico de textos sefardíes», financiado por el MINECO [ref. núm. FFI2016-74864-P]. Una versión abreviada del mismo fue presentado como comunicación en The Seventeenth World Congress of Jewish Studies, sección: Sephardic Studies, celebrado en la Universidad Hebrea de Jerusalén los días 6-10 de agosto de 2017.

**elena.romero@cchs.csic.es

Copyright: (C) 2019 CSIC. Este es un artículo de acceso abierto distribuido bajo los términos de la licencia de uso y distribución Creative Commons Reconocimiento 4.0 Internacional (CC BY 4.0). 
Keywords: Sephardic aljamiado Literature; Sephardic Translations of Hebrew Texts; Midrash; Gedulat Moshe; Petirat Moshe; Ma 'ase Yerushalmi; Sefer Ben-Sirá.

\section{Contenido y materiales usados}

En el presente artículo y a través de ejemplos pretendo mostrar el desconocimiento o incomprensión del hebreo del que, en ocasiones, hacen gala los sefardíes. Mi argumentación se basará en dos tipos de errores: 1) en primer lugar los gráficos, en los que las palabras hebreas aparecen escritas a la «fonética» en impresos y en manuscritos, lo que en el caso de los impresos, y como luego diré más ampliamente, induce a pensar en una composición tipográfica al dictado; y 2) en segundo lugar los errores que muestran la incomprensión de textos hebreos a la hora de traducirlos al judeoespañol, lo que puede dar como resultado versiones, bien incomprensibles, bien hilarantes por disparatadas. En uno y otro caso -errores gráficos y malas traducciones del hebreo- me limito a comentar aquí algunos pocos ejemplos de los cientos que podría aducir.

Mis ejemplos provienen mayoritariamente de las versiones judeoespañolas de los midrašim hebreos Guedulat Mošé y Petirat Mošé. La edición y estudio de tales textos pueden verse en mi libro El profeta Moisés: Su grandeza y su muerte ${ }^{1}$.

Pero no ha sido esta la primera vez que me he ocupado de los errores de entendimiento cometidos por traductores sefardíes al enfrentarse a textos hebreos. Dejaba sobrada cuenta de ello en las notas de mi añejo artículo, que apareció en Sefarad en 1995, sobre una versión judeoespañola, publicada en Constantinopla en 1823, del relato hebreo Ma'asé Yerušalmi ${ }^{2}$, y también me ocupaba de ello en mi libro Andanzas y prodigios de Ben-Sirá ${ }^{3}$, con la edición de la versión judeoespañola del relato

${ }^{1}$ Elena Romero, El profeta Moisés, divino y humano: su grandeza y su muerte. Versiones sefardies de dos leyendas hebreas medievales (Madrid: CSIC, 2017).

2 Elena Romero, «Una versión judeoespañola del relato hebreo Ma 'asé Yerušalmí», Sefarad 55:1 (1995) págs. 173-194.

3 Andanzas y prodigios de Ben-Sirá: Edición crítica de las versiones judeoespañolas impresas y traducción del texto hebreo (Venecia 1544) (Madrid: CSIC, 2001). 
hebreo del Séfer Ben-Sirá, aparecida en la misma edición citada de Constantinopla 1823.

Aunque en estos casos -Yerušalmí y Ben-Sirá- se trata de ejemplos que ya circulan, para completar el cuadro y que no todo proceda de los textos dedicados a Moisés, voy a repetir aquí algunos de los muchos errores presentes en esos textos sefardíes.

Para mis ejemplos me sirvo de las siguientes ediciones y manuscritos ${ }^{4}$.

Del Guedulat Mošé uso las ediciones que vieron la luz en: Salónica 1855A (S855A) $)^{5}$ y 1855B (S855B); Belgrado 1860 (B860); y Salónica 1891 (S891); a las que se suma un manuscrito de Tetuán de 1891 (MsT891); cito también la edición de Constantinopla ca. 1765 (C765?) $\mathrm{y}$ un manuscrito fechado por aproximación en Oriente siglo XIX (MsOr850?). En la comparación con el texto hebreo remito a las ediciones de Salónica 1747 ( $S 747 h)$ y Salónica ca. 1750? (S750?h), así como a la edición de A. J. Wertheimer en su Baté Midrašot ${ }^{6}$.

En cuanto al Petirat Mošé uso las ediciones de: Constantinopla 1763 (C783); Burgás (Bulgaria) 1919 (Br919); amén del citado manuscrito de Oriente del siglo XIX (MsOr850?). En cuanto a las fuentes hebreas me sirvo de las que vieron la luz en Liorna 1795 (L795) y 1931 (L931), así como a las ediciones de Buber en su Midráś Tanhuma ${ }^{7}$; y de Pérez Fernández y Ruiz-Morell, en su El beso de $\operatorname{Dios}^{8}$, donde se incluye la traducción al español del Midrášs Rabáa a Debarim.

${ }^{4}$ De todas las obras que cito a continuación en relación con Guedulat y Petirat, tanto de textos judeoespañoles, como de fuentes hebreas, pueden verse datos detallados en mi libro citado en nota 1 supra.

5 A partir de ahora cito siempre los textos por estas abreviaciones que indico entre paréntesis.

${ }^{6}$ Aaron J. Wertheimer (ed.), Baté midrašot (1. ${ }^{a}$ ed. 4 vols., Jerusalén 1893-1897; 2. ${ }^{a}$ ed. 2 vols., Jerusalén: Ktab wasepher, 1968; uso la 2. a ed.), vol. I, págs. 262a-264b.

7 Salomon Buber (ed.), Midráš Tanḥuma hacadum vehayašán... 'al ḥamišá ḥumšé Torá, 2 vols. (Vilna 1885 o 1887; reimpr. Israel sin fecha, quizá Jerusalén 1964), vol. II.

8 Miguel Pérez Fernández y Olga Ruiz Morell, El beso de Dios, midrás de la Muerte de Moisés, Edición bilingüe hebreo-español y comentario (Estella: Editorial Verbo Divino, 2013). 
Para las versiones sefardíes de los relatos Ma 'asé Yerušalmí y Séfer Ben-Sirá ${ }^{9}$ uso la edición de Constantinopla 1823. Y en la comparación con los textos hebreos, para el Yerušalmí me sirvo de la edición de J. L. Zlotnik en su Ma 'asé Yerushalmí ${ }^{10}$, sobre la primera de Constantinopla 1518; y para Ben-Sirá de la edición de Venecia 1544.

\section{ERRORES GRÁFICOS}

Veamos en primer lugar una pequeña muestra de los muchos ejemplos que podría aducir en el tema de los errores gráficos.

Que los impresores sefardíes han escrito con frecuencia las palabras hebreas con una grafía que podemos llamar «a la fonética», no es desde luego un descubrimiento mío, sino un fenómeno detectado desde antiguo ${ }^{11}$.

Con frecuencia se ha entendido el fenómeno como un recurso «humorístico» y ello porque un buen número de periódicos sefardíes encuadrados en tal género han usado y abusado de tal tipo de grafias. Sin embargo ello no es del todo cierto, lo que puedo afirmar por una experiencia personal. Cito como ejemplo el libro del muy conocido editor y autor Šemuel Sa'adi Haleví, titulado Flama acendida y que apareció en Salónica en 1922, en donde el autor nos relata un sueño que finge haber tenido sobre las reacciones que hubieran sido esperables y que no se produjeron por parte de los sefardíes de Salónica establecidos en Suiza cuando les llegó la noticia del incendio que había asolado su ciudad natal en 1917. Al leer tal libro en el que Haleví se refiere al terrible incendio y a sus trágicas consecuencias para la comunidad sefardí de Salónica, tema, por tanto, nada humorístico, me encontré con tal canti-

${ }^{9}$ Véanse datos bibliográficos precisos en mis estudios recogidos en notas 2 y 3 supra.

10 Jehuda L. Zlotnik et al., Ma'asé Yerushalmi (The Story of the Jerusalemite) (Jerusalem, 1946 [en hebreo]) págs. 44-67.

11 Baste poner como ejemplo el libro de David M. Bunis, A Lexicon of the Hebrew and Aramaic Elements in Modern Judezmo (Jerusalem: The Magnes Press-The Hebrew University-Misgav Yerushalayim, 1993), donde el autor aduce numerosas grafías de ese tipo. 
dad de hebraísmos mal escritos que decidí escribir un artículo al respecto, artículo, que como tantas otras cosas, se me ha quedado en el cajón de los recuerdos.

Pasemos ya a ver los ejemplos que ordeno alfabéticamente, algunos de los cuales también podrían considerarse como malas traducciones. En primer lugar me ocupo de los que se encuentran en Guedulat seguidos de los de Petirat. Marco en negrita las palabras en discusión y entre paréntesis indico la edición o el manuscrito en que aparecen. En el caso de frases bíblicas indico entre corchetes la precisión de libro, capítulo y versículo. Con la indicación de (Bunis + un número) remito al libro citado en nota 11 y al número donde se recoge la palabra.

\subsection{Ejemplos de Guedulat}

- apicados, en la frase «Dos mil alacranes apicados en ellos», escrito אפיקאדוס (Guedulat B860). Pero en la fuente hebrea ( $S 747 \mathrm{~h}$ h. $4 \mathrm{~b})$ se dice דבוקים debuquim, que otras versiones sefardíes traducen bien por apegados. Puede tratarse de un error gráfico de guímal por cof.

- kod, en la frase «Yo te daré kod», escrito כוד $<k w d>$ (Guedulat S855B), para hb. כבוד kabod.

- malajim, escrito מלכים (Guedulat B860), grafía que corresponde a hb. melajim 'reyes', pero que aquí se trata de מלאכים mal'ajim 'ángeles'. El error se repite en otras ocasiones.

- resa'im, escrito ריסעים (Guedulat MsT891), para hb. רשעים reša 'ím 'malvados', palabra que aparece con frecuencia bien escrita.

- rošjem, en la frase «Lo taquifu peat rošjem», escrito ראשכים (Guedulat B860), lo que en el texto bíblico [Lev 19:27: 'No raparéis los aladares de vuestras cabezas'] es ראשכם סאם

- sam, escrito סאם (Guedulat B860), para hb. סם 'veneno'.

Cabe señalar que, de los seis ejemplos, cuatro se dan en la edición de Belgrado de 1860 y uno en la que vio la luz en Salónica 1855 $(S 855 B)$, en tanto que otro más procede del manuscrito de Tetuán de 1891. 


\subsection{Ejemplos de Petirat}

Pasemos a los ejemplos de Petirat.

- Aháźariel, escrito אמזריאל . אמזיאל para hb Ajźariel.

- 'al, escrito על (Petirat Br919) hb. 'sobre', donde en el versículo bíblico dice אל el 'a, hacia': "Vaethanán el Yhvh ba'et hahí lemor [Deut 3:23: 'Y rogó a Dios en aquella hora, dićiendo'].

- arodear, en la frase «Mošé era arodear a la civdad», escrito ארודיאר (Petirat Br919). Pero en las fuentes hebreas (L795 h. 105a y L931 pág. 460) el verbo es mesabeb lit. 'que da vueltas', 'dando vueltas', así que habríamos esperado jsp. arodeán. Puede tratarse de un error gráfico de reš por nun final.

- bad, escrito בד (Petirat Br919), para hb. בת: «Salió bat col» (Bunis 780).

- beźot, escrito וזאת (Petirat Br919), para hb. en «Veźot haḅerajá» [Deut 33:1: 'Y esta es la bendición'].

- Elohenan, escrito אלוהינן (Petirat Br919), para hb. אלוהינו 'nuestro Dios', cambiando la vav final por una nun.

- en, escrito אין (Petirat Br919), para el hb. הן hen 'he aquí' de las fuentes hebreas ( $L 795$ h. 105b y L931 pág. 461), que es la palabra en discusión. Moisés había dicho: «Hen laH' Eloheja hašamáyim ušemé hašamáyim» [Deut 10:14: 'He aquí que al Señor tu Dios pertenecen los cielos y los cielos de los cielos']; y Dios, para anunciarle su muerte, le dice a Moisés: «Hen carebú yameja lamut» [Deut 31:14: 'He aquí que se acercan los días de tu muerte'].

- malaj, escrito מלך (Petirat Br919), grafía que corresponde a hb. mélej 'rey', pero que aquí se trata de hb. מלאך mal'aj 'ángel': "dijo el Dio a el mal'aj Gaḅriel». Tal error también lo hemos visto en Guedulat.

- Miḥael, escrito מיחאל (Petirat Br919), para hb. מיכאל Mijael.

- mntó, escrito con un doble error מנטו מ מ מ לmntw> (Petirat Br919), para hb. מותו 'su muerte': «Lifné motó» [Deut 33:1: 'Antes de su muerte'].

- Og, escrito אוג (Petirat Br919), para hb. עוג 'Og. 
- quefí, escrito קיפ'י (Petirat Br919), para hb. כפי kefi 'según' (Bunis 2031).

- queMošé, escrito קמשה (Petirat Br919), para hb. כמשה 'como Moisés': «Veló cam nabí 'od beYisrael keMošé» [Deut 34:10: 'Y no se alzó en Israel otro profeta como Moisés'].

- qui, escrito קי (Petirat Br919), para hb. כי 'que': «Ki hileŝtá nafší mimávet» [Sal 116:8: 'Que escapaste mi alma de la muerte'].

- raña, en la frase «Esta espada no es raña otro que para el rey», escrito ראנייה (Petirat MsOr850?). Indudable error gráfico, como si el ראוי diña 'digna' o el דינייה din escribir rauy 'adecuada, digna' que aparece en el texto hebreo (Buber pág. 11, núm. 6).

- sar, escrito סאר (Petirat Br919), para hb. צער sá 'ar 'angustia, esfuerzo' (Bunis 3437).

- salaḥti, en la frase «Los perdoní, según tu palabra», escrito סלחטי (Petirat Br919), para hb. סלחתי 'perdoné' [Núm 14:20], donde se ha producido un error gráfico de tet por tav.

- Ŝse'udá, en la frase "se'udá de novio y novia», escrito (Petirat Br919), para. hb. סעודה se 'udá 'banquete'.

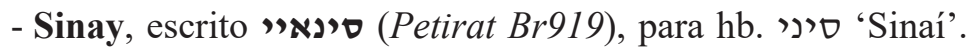

- sofé, escrito סופה (Petirat Br919), para hb. צופה 'mira', según el texto bíblico: «Ŝofé rašá' laŝaḍic umbaquéš lahamitó» [Sal 37:32: 'Mira el malo al justo y busca matarlo].

- tome, en la frase "Todo el que tome de el Dio», escrito (Petirat Br919). Pero en las fuentes hebreas ( $L 795$ h. 105a y L931 pág. 460) dice שמתיירא 'que teme', así que debe tratarse de un error gráfico por טימי teme.

- yadá, en la frase: «UMošé lo yadá' ki carán 'or panav» [Éx 34:29: 'Y Moisés no supo que se esclareció la luz de su cara'], escrito ידה (Petirat Br919), para hb. ידע 'supo'.

- Yardén, escrito ירדון (Petirat Br919), para hb. ירדין 'Jordán'.

En este caso de 23 ejemplos, 22 proceden de la edición de Burgás de 1919 y uno solo del manuscrito de Oriente ca. 1850. 


\subsection{Comentario a los errores gráficos}

Y ahora voy a especular un poco sobre este tipo de errores. Cierto es que varios nos están reflejando la pronunciación sefardí del hebreo entre las gentes de a pie. Recuerdo muy bien a mi suegra que, por ejemplo, nunca decía šaḅat ni Šabu 'ot, sino sabá y Sabuó. Pero, en el caso de los impresos, cabe también otra explicación: la de escribir al dictado.

Los más ancianos lectores de Sefarad, entre los que desde luego me cuento, quizá hayan tenido ocasión de ver cómo trabajaban hace muchos años los tipógrafos. Yo sí he tenido la oportunidad de contemplar, asombrada en mi ignorancia juvenil, las labores de los tipógrafos de la imprenta Bermejo, encargada de la impresión de la revista Sefarad. Cuando el trabajo era mucho y corría prisa terminarlo, lo cual pasaba prácticamente siempre, un lector se situaba junto al encargado de coger con unas pinzas los tipos del chibalete y ponerlos en las regletas de la caja y le iba leyendo el texto que había que componer.

Claro está que no he visto con mis propios ojos cómo funcionaban las imprentas sefardíes de los Balcanes, pero como el oficio es el mismo, no es impensable pensar que lo que he descrito también ocurriera en dichas imprentas y que el tipógrafo escuchaba y no leía él mismo el texto que iba a componer. Ese tipógrafo tampoco tenía porqué saber hebreo -incluso sabemos de imprentas regidas por armenios que componían libros aljamiados- $y$, en consecuencia no distinguiría entre aquellas letras que en hebreo tienen el mismo sonido, como son los casos que hemos visto supra de errores entre las siguientes letras: het por jaf-en Ahźariel, Mihael-; tet por taf-en selahti-; kaf por cof-en quefí, queMošé, qui-; bet por vav-en beźot-; etc.

Tampoco estarían capacitados esos tipógrafos para corregir las posibles malas pronunciaciones del lector en sonidos como los siguientes: el de la ŝade -con sámej en sofé y sar-; de la šin-con sámej en resa 'im-; la ausencia del sonido de la 'ayin -en $O g$, sar y yadá-; la siempre conflictiva pronunciación castellana de determinadas consonantes finales -como en bad por bat-; la no pronunciación aspirada de la hé -como en en por hen-; a lo que habría que añadir las adiciones por cuenta del tipógrafo de matres lectionis -como en sam, Sinay, Yardén-; etc. 
En el caso de que el tipógrafo sí estuviera leyendo él mismo de un manuscrito o de otro impreso anterior que tuviera delante, algunos errores se justifican por la urgencia y precipitación en coger los tipos de imprenta, provocadas por la confusión entre letras de formato parecido en letra raší, como es el caso de las siguientes: guímal - nun medial; vav - yod; y tet-mem medial - sámej. Recordemos los ejemplos que hemos visto de tome por teme, Elohenan por Elohenu, mntó por motó, así como otros que veremos a continuación ${ }^{12}$.

Sabemos que las imprentas sefardíes tenían correctores de pruebas algunos de cuyos nombres nos han llegado. Y así, por ejemplo, en la edición del Guedulat de Belgrado 1860 se nos dan los nombres del tipógrafo y del corrector:

Nišlam hamelajá ['Se acabó el trabajo'] [...] 'al yedé ha'osec bimléjet hacodeš haŝa'ír ['por mano del que se ocupa de la obra santa (es decir, del tipógrafo), el joven'] Šelomó Šimšón Ḥabillo [...], hamag̉uíah ['el corrector de pruebas'] [...] David b" Mošé Alcala ‘i [...].

Y aún encontramos allí la siguiente advertencia:

Se da a saber a los señores meldadores ['lectores'] seer [sic] toparán algunos yeros, sepan que la obra de el defús ['imprenta'] no ella en muestra mano, que por ello no mośotros culpośos.

Si aduzco tal frase es porque efectivamente en el breve pasaje del Guedulat que incluye la obra, inserta en una versión judeoespañola del midráš 'Aséret hadiḅerot, he encontrado numerosos errores, siendo esta la edición más descuidada ya que, como he señalado antes, de mis seis ejemplos cuatro aparecen en esa edición de Belgrado de 1860 .

12 Sobre los errores gráficos en textos sefardíes al escribir palabras hebreas, vid. también el libro de Aitor García Moreno y Moisés Orfali, La saga de los reyes otomanos. Edición crítica y estudio de tres versiones del Séfer Sipur maljé 'otmanlim (Constantinopla 1767 y 1863, y Kazanlâk 1815) (Granada: Editorial Universidad de Granada, 2018) apartado 1.3.1.1, págs. 53-55, así como la bibliografía citada en la nota 58. 


\section{EJEMPLOS DE MALAS O SORPRENDENTES TRADUCCIONES}

Pasemos ya al segundo grupo antes mencionado; el de los ejemplos de malas o sorprendentes traducciones. Y repito lo ya dicho: que lo que comento aquí es solo una muy pequeña parte de los cientos de ejemplos que podría aducir y que solo voy a referirme a algunos casos que me parecen paradigmáticos.

Con frecuencia me he encontrado en los midrašim de los que nos estamos ocupando con ciertas malas traducciones del hebreo, que sólo se pueden explicar porque el manipulador del texto -ya sea traductor, impresor o manuscriba- ha tenido delante un texto hebreo que no ha sabido interpretar correctamente.

La presentación de los ejemplos sigue la misma pauta de los anteriores, si bien ahora veremos primero los ejemplos de Petirat y luego los de Guedulat.

\subsection{Ejemplos de Petirat}

1. «¿Con la cośa que te alabí entre sesenta milarias ${ }^{13}$ santificantes tu nombre, con él asenteciates sobre mí muerte?» (Petirat Br919).

En las fuentes hebreas (L795 h. 105b y L931 pág. 461) dice בדבר badabar, que aquí hay que entender 'con la palabra', mejor que 'con la cosa', por mucho que en hebreo dabar tenga ambos significados.

2. «Mos anỵeźa ['enseña'] que estas diez većes fue asetenciado sobre él que no va entrar a Ereŝ Yisrael», escrito איסטאס (Petirat Br919).

Pero en las fuentes hebreas ( $L 795$ h. 105b y L931 pág. 461) dice שעד עשרה פעמים še 'ad 'asará pe 'amim 'que hasta diez veces'. Parece que el manipulador sefardí o el impresor han confundido el esperado jsp. איסטה hasta conadiendo una sámej al final por mantener la concordancia con «diez većes».

13 Según Éx 12:37 y Núm 11:21 ese es el número de las gentes que Moisés sacó de Egipto. 
3. «Cuánto sar me tomí por ellos en las miŝvot hasta que atestigüí a ellos Ley y miŝvot» (Petirat Br919).

Con atestigüi se traduce el hb. שקבעתי 'que fijé, que establecí' de las fuentes hebreas (L795 h. 106a y L931 pág. 462). Quizá se trate en este caso de un error gráfico por jsp. asetiguar 'fijar, establecer'.

4. «Hasta que le quedó a Mošé una hora», escrito קי (Petirat Br919).

Pero en las fuentes hebreas (L795 h. 106a y L931 pág. 462) dice עד כאן 'ad kan 'hasta aquí'. La diferencia de traducción quizá podría explicarse por un error tipográfico o también por una mala lectura de un texto judeoespañol previo donde estuviera escrito אקי aquí.

5. «Se ensañó Mošé y tomó a la vara que en su mano, que estaba cavacado el nombre de el Dio, y encontró a el SM» (Petirat Br919).

En las fuentes hebreas (L795 h. 106b y L931 pág. 463) dice vepagá 'bo beSamael 'y golpeó con ella a Samael', que también puede entenderse 'y golpeó en él en Samael'. El traductor sefardí ha optado aquí erradamente por el otro significado que tiene en hebreo el verbo פגע 'encontrar'.

6. «Mošé, mete tus ojos uno enriba de otro» (Petirat Br919).

En las fuentes hebreas (L795 h. 106b y L931 pág. 463) la frase tampoco resulta muy comprensible: תשקף עיניך זה על גב זה tišcaf 'eneja źe 'al gab źe 'cierra tus ojos uno sobre otro', lo que no parece muy fácil de hacer. Pérez-Ruiz (pág. 177, pár. 12) en su traducción a Debarim Rabá 11:10 han optado por facilitar las cosas, diciendo: «cierra tus párpados uno sobre otro».

7. «¿Hay puerpo limpio en el mundo más de el puerpo de Mošé, que no fue visto en él esprito de altigüeźa?» (Petirat Br919).

En las fuentes hebreas (L795 h. 107a y L931 pág. 464) el texto es muy diferente: שלא נראה בו מעולם רוח סרוחה ולא רמה ותולעת šeló nir'é bo me 'olam rúah seruhá veló rimá vetolá 'at 'que no se vio en él jamás olor fétido, ni gusano ni lombriz'. Parece que el traductor sefardí ha leído la palabra רמה rimá 'gusano' como רמה ramá 'altura, elevación' y la ha traducido, según las expresiones hebreas רמות ramut y ramut rúah, por 'orgullo, soberbia, altivez'. Aunque quizá 
también podría tratarse de una autocensura, no sea que alguien pudiera creerse que Moisés oliera mal y estuviera plagado de parásitos.

8. "Y Mošé no supo que se esclareció luź de sus caras» (Petirat Br919), según ומשה לא ידע כי קרן עור פניו UMošé lo yadá' ki carán 'or panav [Éx 34:29].

El traductor sefardí ha leído aquí y un poco más abajo el hb. עור 'tez, piel (de la cara)' del versículo bíblico y de las fuentes hebreas (L795 h. 104a y L931 pág. 458) como si estuviera escrito אור 'luz'.

Como vemos, los ocho ejemplos proceden de la edición de Burgás 1919.

\subsection{Ejemplos de Guedulat}

Pasemos a ver los ejemplos de Guedulat.

1. «Y mal'ajim dañadores aparej́antes para ellos con cadenas de fiero» (Guedulat B860).

En la fuente hebrea ( $\$ 747 \mathrm{~h}$ h. $4 \mathrm{~b})$ está escrito מכין makin 'golpean', participio de presente plural de la forma hif'il de la raíz J.J. n.k.h, y como tal se ha traducido en las otras versiones sefardíes (S855, C765? y MsT891) mediante los verbos judeoespañoles aharban / harbándolos / harbaban. Pero en $B 860$ con su aparejantes parece haberse entendido erróneamente la palabra hebrea como מכין mejín, participio presente pero singular -cuando el sujeto es plural: los ángeles- de la forma hif'il de la raíz †.ı. k.w.n 'preparar, disponer'.

2. «Vido allí kitot de mal'ajim con saetas de fuego» (Guedulat S855A, S891 y MsT891).

En las fuentes hebreas $(S 747 h$ y $S 750 ? h)$ la palabra aquí traducida por saetas es חציים hasayim 'mitades', como bien traducen otras versiones sefardíes (C765? y MsOr850?). El error se ha producido por haber interpretado la palabra como חצים hisim 'flechas, saetas'.

3. «Subió Mošé a el cielo segundo, que asemeja al día segundo de la semana. Vido allí un mal'aj que su longura trećientas mías ['millas'] 
y cincuenta milarias de mal'ajim diván»", escrito דיב'אן (Guedulat S855 y $S 891)$.

En los textos hebreos (Wertheimer Baté Midrašot vol. 1, núm. 4, pág. 278, y en $S 747 h$ h. 2a y $S 750$ ?h h. 7b) se dice עומדים לפניו 'omedim lefanav 'están de pie delante de él' (lo que en C765? se traduce parados «delantre de él», y en MsOr850? «están delantre de él»). Creo que hay que poner la palabra en relación con la expresión turca divan dur- 'permanecer de pie en actitud respetuosa, con los brazos cruzados delante del pecho'. Prefiero esta posibilidad a suponer la palabra derivada de fr. devant 'ante, delante de'.

4. «Subió Mošé a el cielo tercero y vido ahí un mal'aj y su altura quinientos años. Y tenía setenta mil cabezas, y cada cabeza tenía setenta mil bocas, y cada boca setenta mil lenguas, y en cada lengua setenta mil yeśḅas» (Guedulat MsT891).

La última palabra está escrita ביזבאס, que no puede ser otra cosa que 'avispas, abejas' ${ }^{14}$. En otras versiones sefardíes -excepto en $S 891$, que omite la frase, y en $B 860$, que omite el pasaje- encontramos aquí palabras como hablas (en $S 855$ y MsOr850?) y comandamientos (en C765?), que se ajustan al sentido del texto.

El error puede venir justificado por las anómalas grafías de las fuentes hebreas. En el texto hebreo de Wertheimer (vol. 1, núm. 5, pág. 278) la palabra está escrita דיבור dibur; pero en las ediciones hebreas de Salónica $-S 747 h$ (h. 2a) y $S 750 ? h$ (h. 7b)- se lee דבורות >dbwrwt>. Esta grafía de las ediciones salonicenses puede ser una forma incorrecta del plural de hb. דברה dibrá, que sería debarot y no de/iburot, o un plural anómalo del mencionado hb. דבור dibur, que por ser masculino hace el plural en דבורים diburim, y no diburot. En cualquier caso, tanto la palabra dibrá como dibur, en plural significan lo que traducen las otras versiones sefardíes: 'dichos, hablas' o también 'mandamientos, órdenes', como se interpreta en el comandamientos de C765?, lecturas todas ellas que concuerdan con el sentido del texto.

\footnotetext{
${ }^{14}$ Cfr. Joseph Nehama, Dictionnaire du Judéo-Espagnol (Madrid: CSIC, 1977) s. v. bézba.
} 
La dificultad señalada en la palabra hebrea parece haber llevado al huerto al manuscriba de MsT891 que nos deja una perla de entendimiento, ya que allí nos encontramos con ese inusitado yeśḅas, lo que deja la idea de que las lenguas de los ángeles eran un muy poblado avispero (hemos oído hablar de las «lenguas viperinas», pero no «avisperinas»).

Sin embargo no le faltaba alguna razón a nuestro manuscriba, ya que la palabra hb. דבורה deborá significa precisamente 'avispa'; lo único que hay que objetar a tal lectura es que, por mucho que el hb. deborá sea femenino, su plural es דבורים deborim, es decir, masculino (iprioridades de los zánganos!).

De los cuatro ejemplos que he aducido, dos son singulares de una sola versión: los aparejantes de B860 (núm. 1), y las yeśḅas de MsT891 (núm. 3); y otros 2 son compartidos: las saetas, presentes en $S 855 \mathrm{~A}$, S891 y MsT891 (núm. 2); y el diván que aparece en $S 855$ y $S 891$ (núm. 3). Y es relevante destacar la importancia de las traducciones compartidas, ya que en muchas ocasiones el mantenimiento de traducciones inusitadas en ediciones y manuscritos de diferentes fechas y lugares nos ayuda a establecer familias de versiones y a determinar las interdependencias.

\subsection{Comentario a las malas traducciones}

Con los pocos ejemplos que he presentado puede mostrarse las dificultades que podían tener, sino todos, al menos algunos de los adaptadores sefardíes que vertían al judeoespañol textos hebreos. Los errores de comprensión se producen, sobre todo, en las ediciones y manuscritos más recientes -mediados del siglo XIX-, fechas en las que nos consta que habían disminuido las academias rabínicas en las comunidades sefardíes por falta de alumnos interesados en tales estudios, lo que implicaba un menor conocimiento del hebreo.

He mostrado solo errores de traducción, pero también con frecuencia es sintomática la omisión de pasajes que suelen coincidir con textos cuyas formulaciones en hebreo no están muy claras. 
4. EJEMPLOS DE MALAS TRADUCCIONES EN OTROS TEXTOS SEFARDíES DE ORIGEN HEBREO

Como anunciaba al principio, voy a completar este cuadro con cinco ejemplos de traducciones disparatadas tomados tres del Ma 'asé Yerušalmí y dos del Séfer Ben-Sirá.

\subsection{Ejemplos de Ma'asé Yerušalmí}

1. «Era varón sabién meldar y vido el Dio».

וירא : Frase esta última que queda sin sentido. El texto hebreo dice השם viré haŠem 'y temeroso del Nombre (= Dios)'. Resulta obvio que el traductor sefardí ha leído viré, de la raíz ויר y.r.', como vayar, de la raíz $r$. r.'h y de ahí su disparatada traducción que deja la frase $\sin$ sentido $^{15}$.

2. «su din para pešquerir juicio y para apalpar en su din».

El texto hebreo dice: דינו לבקר משפט ופשפשו לדינו dinu labóquer mišpat ufašpešú ledinó 'sentenciad por la mañana el juicio e investigad [dictad] su sentencia'. En la desgraciada frase se han cometido varios errores: el dinu 'sentenciad' inicial se ha leído como dinó 'su din'; labóquer 'por la mañana' se ha entendido como lebaquer 'preguntar, investigar', de ahí el pešquerir del texto judeoespañol; y para guinda de la tarta ufašpešú, del verbo hebreo lefašpéś 'investigar, examinar con detenimiento', se ha leído como למשמש lemašméš 'tocar, palpar' ${ }^{16}$.

3. «¿Para modre de qué tú eres pestañudo?».

La última palabra en hb. es גבן guibén 'jorobado'. El traductor sefardí גבה גarece haberse confundido con algún inexistente derivado hebreo de gaḅá 'ceja' que le ha llevado al hilarante pestañudo ${ }^{17}$.

15 Vid. ROMERo, «Ma‘asé Yerušalmí», pág. 179 y nota 17.

16 Vid. Romero, «Ma'asé Yerušalmí», pág. 181, notas 22-23.

17 Vid. Romero, «Ma‘asé Yerušalmí», pág. 186 y nota 30. 


\subsection{Ejemplos de Ben-Sirá}

1. «En la hora que dijo David a Limfibóšet».

En el texto hebreo dice: בשעה שאמר דוד למפיבשת beša'á šeamar David liMfibóšet 'En la hora que dijo David a Mefibóset'. Tal y como está escrito en el texto judeoespañol parece que el traductor sefardí ha creído que el nombre del tullido hijo de Jonatán es Limfibóšet ${ }^{18}$.

2. «No a mí licencia para enviar sino dos, que su pricipio de sus nombres por cavśa de cuervo y palomba».

En el texto hebreo, en donde se ha establecido un diálogo entre Noé y el cuervo, se dice: אין לי רשות לשלוח אלא שנים שהתחלת שמם עaל en li rešut lišlóaḥ ela šenáyim šehathalat šemam "'y 'oreb yoná 'no tengo licencia para enviar sino a dos cuyos nombres empiezan [por las letras] 'a[yin y] y[od]: cuervo paloma', en donde resulta obvio que la presencia de comillas entre las letras 'ayin y yod, iniciales de 'oreb 'cuervo' y yoná 'paloma', ha inducido al traductor sefardí a suponer que se trata de la abreviatura hebrea de 'al yedé que traduce 'por cavśa de' ${ }^{19}$.

\section{Conclusión}

Como conclusión quiero solamente hacer hincapié en lo evidente: la problemática que se nos plantea a los estudiosos que nos ocupamos de la edición de estas versiones sefardíes basadas en textos hebreos para su correcta elucidación y explicación.

En nuestro proceso de comparación debemos, en no pocas ocasiones, imaginarnos cual ha sido el proceso del cerebro del traductor sefardí al encontrarse con palabras o formulaciones hebreas que no entiende y que le llevan a cometer errores. A veces lo logramos y a veces no, pero en cualquier caso, la labor es siempre apasionante.

18 Vid. Romero, Andanzas y prodigios, págs. 32-33 y nota 82 y págs. 212-214 y nota 206.

19 Vid. Romero, Andanzas y prodigios, pág. 33 y nota 83 y pág. 132 y nota 293. 
Y aún quiero mencionar otras dos cuestiones que no a todos los estudiosos del ramo les parecen tan evidentes como a mí: 1) que los investigadores deben ser conscientes de que para penetrar en los problemas que plantean los textos sefardíes de determinados géneros es imprescindible conjugar sus conocimientos de hispanistas con los de hebraístas; y 2) que los estudiosos sefardíes conocedores de hebreo no pueden llevar a cabo con solvencia la edición de textos sefardíes de siglos pasados sin tener un buen conocimiento de español.

Recibido: 10/04/2018

Aceptado: 18/02/2019 
